be that budding is confined to the spleen, and that resulting erythroplastids are rapidly destroyed in the Anura, but persist in Batrachoseps and to a lesser degree in other urodeles.

Department of Phyşiology,

University of Cape Town, South Africa.

Aug. 8.

${ }^{1}$ Emmel, V. E., Amer. J. Anat., 33, 347 (1924).

2 Duran-Jorda, F., Acta med. Scand., 40, 183 (1951).

3 Jordan, H. E., and Spiedel, C. C., Amer. J. Anat., 32, 155 (1923).

- Dawson, A. B., Amer. J. Anat., 42, 139 (1928).

\section{Hatching the Contents of Cysts of Heterodera rostochiensis with Alternating Temperature Conditions}

Ir is well known that the larve of the potato root eelworm, $H$. rostochiensis, are stimulated to emerge from the eggs contained in the cysts by a secretion from the roots of growing potato plants. This root diffusate can be collected and used in the laboratory. Anhydrotetronic acid is also an effective stimulant.

It has been found that an alternation of a high with a low temperature during the hatching of $H$. rostochiensis, with either root diffusate or anhydrotetronic acid, leads to a significant increase in the number of larvæ emerging from a batch of cysts.

Experiments have been conducted in which weekly counts have been made to observe the effect of hatching the cyst contents when : (a) a temperature of $25^{\circ} \mathrm{C}$. is constantly maintained ; $(b)$ the temperature is lowered from $25^{\circ}$ to $15^{\circ} \mathrm{C}$. for $5 \mathrm{hr}$. twice a week ; (c) the temperature is lowered from $25^{\circ}$ to $15^{\circ} \mathrm{C}$. for $5 \mathrm{hr}$. five times a week.

The results shown below were obtained from several experiments with potato root diffusate.

NUMBer OF LARV me marerging FroM BATCHES OF ONE HUNDRED CYSTS (MEAN OF FOUR REPLICATES) AFTER TWELVE WEERS TREaTMENT

\begin{tabular}{|l|l|c|c|c|}
\hline Exp. & $\begin{array}{c}\text { Constant } \\
\text { No. }\end{array}$ & $\begin{array}{c}\text { Alternating temperature } \\
\text { Twice a } \\
\text { week }\end{array}$ & $\begin{array}{c}\text { Five times } \\
\text { a week }\end{array}$ \\
\hline 1 & Non-vintage cysts* & $\mathbf{5 , 7 3 9}$ & $\mathbf{1 1 , 1 5 7}$ & $\mathbf{1 3 , 2 0 1}$ \\
2 & Non-vintage cysts & 6,222 & 8,355 & 11,118 \\
3 & Vintage cysts & 11,370 & 17,530 & 26,819 \\
4 & Vintage cysts & 13,126 & 18,421 & $\mathbf{2 6 , 3 2 4}$ \\
\hline
\end{tabular}

* Vintage cysts are cysts of a known age.

A hatching treatment which includes an alternation of temperature probably offers conditions more nearly approximating to those in the soil than one in which the temperature is kept constant, and may help to obtain a complete hatch of larvæ from eelworm cysts.

Imperial College Field Station,

Daphne D. Bishop

Sunninghill, Berks.

\section{Rate of Activity as a Function of Intertidal Height within Populations of some Littoral Molluscs}

THE physiological reality and profound ecological significance of the phenomenon of regulation of rate functions towards a constant, in response to maintained temperature differences, within the species in poikilotherms, has been widely recognized in recent times. Much attention has been directed in this

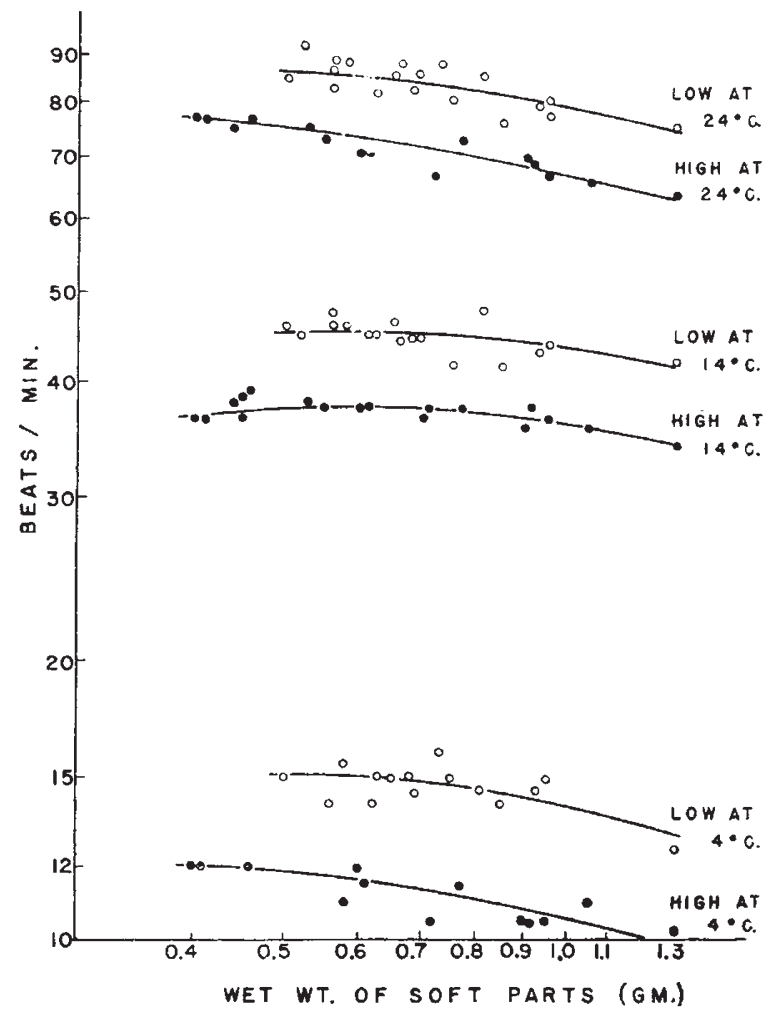

Fig. 1. Relation between frequency of heart-beat and wet weight of soft parts, at various temperatures, in A cmaea limatula from uals from a permanently submerged level ; filled circles represent mid-tide individuals from a level (3-4 ft. above zero datum, U.S. Coast and Geodetic Survey Tide Tables), submerged 40-50 per cent of the time. Points are averages of three readings for ten beats each

connexion to a study of populations spatially separated by a wide range of latitude ${ }^{1-3}$ or temporally separated by the annual cycle of seasons ${ }^{4,5}$. Indications of the existence of similar intraspecific differences between high and low members of populations of intertidal invertebrates are reported in the present communication.

'The lower in the normal intertidal range of dis. tribution limpets of the species Acmaea scabra and $A$. limatula are collected, the higher the rate of heart-beat at any given temperature. This is shown, with weight controlled, in Fig. 1. The heart has been exposed by a trephine hole in the shell, after which the rate of beat settles down shortly to a rather uniform value for many days. Counts were made three days after collecting and trephining; the animals were kept in the meantime in standing, aerated sea water at $14^{\circ} \pm 0.5^{\circ} \mathrm{C}$., changed daily. Two hours was allowed for equilibration at each temperature. The regime of temperatures and of handling in collecting, operating and counting, while not critical, has been carefully standardized for the data on $A$. limatula. A few counts were discarded because of excessive locomotor activity or irregularity of heart-beat.

Mussels (Mytilus californianus) show the same relationships (Fig. 2) when rate of propulsion of water is measured by photoelectric estimation of clearing rate of dilute colloidal graphite suspensions ${ }^{3,6}$. Each point on the graph represents the average of three measurements for each individual in a group 